
$\mathrm{Kie})$

\title{
Komunikasi Pemasaran Word of Mouth dan Electronic Word of Mouth dalam Mempertahankan Brand Existence (Studi Kasus pada Kopi Es Tak Kie)
}

\author{
Nevelyn Anestya Herdian, Diah Ayu Candraningrum \\ Nevelyn.915150098@stu.untar.ac.id,diahc@fikom.untar.ac.id \\ Fakultas Ilmu Komunikasi Universitas Tarumanagara
}

\begin{abstract}
Es Tak Kie Coffee is an old coffee shop that has been established since 1927 and this shop is 92 years old today. The Kopi Es Tak Kie brand has had 3 generations from generation to generation. The purpose of this study was to find out word of mouth marketing communication and electronic word of mouth communication in maintaining brand existence in the Kopi Es Tak Kie brand. This study uses a descriptive qualitative approach, using the case study research method. Data collection techniques are carried out through nonparticipant observation, interviews, documents and online data tracking. Based on the results of interviewing the researcher with the informant, getting data about that the Kopi Es Tak Kie brand is a typical marketing and selling method for coffee shops, ranging from traditional to modern marketing. Based on this research, it can be concluded that communication of word of mouth marketing and electronic word of mouth is an important role in the Es Kopi Kie brand. There is customer satisfaction that leads customers to be loyal. Customers talk about the Kopi Es Tak Kie brand until it is widely known to the public, so as to maintain the continuity of the business of the Kopi Es Tak Kie brand until now.
\end{abstract}

Keywords: Marketing Communication, Word of Mouth, Electronic Word of Mouth.

\begin{abstract}
Abstrak
Kopi Es Tak Kie adalah kedai kopi tua yang telah berdiri sejak tahun 1927 dan kedai ini sudah berumur 92 tahun sampai saat ini. Merek Kopi Es Tak Kie sudah memiliki 3 generasi turun-temurun. Tujuan dari penelitian ini adalah untuk mengetahui komunikasi pemasaran word of mouth dan electronic word of mouth dalam mempertahankan brand existence pada merek Kopi Es Tak Kie. Penelitian ini menggunakan pendekatan kualitatif yang bersifat deskriptif, dengan menggunakan metode penelitian studi kasus. Teknik pengumpulan data dilakukan dengan melalui observasi nonpartisipan, wawancara, dokumen dan penelusuran data online. Berdasarkan hasil dari wawancara peneliti dengan informan, mendapatkan data mengenai bahwa merek Kopi Es Tak Kie terdapat cara pemasaran dan berjualan yang khas pada kedai kopinya, mulai dari pemasaran tradisional sampai modern. Berdasarkan dari penelitian ini, dapat disimpulkan bahwa komunikasi pemasaran word of mouth dan electronic word of mouth merupakan peran penting pada merek Kopi Es Tak Kie. Terdapat kepuasan pelanggan yang menggiring pelanggan menjadi loyal. Pelanggan membicarakan merek Kopi Es Tak Kie hingga dikenal publik secara luas, sehingga dapat mempertahankan kelangsungan usaha merek Kopi Es Tak Kie hingga sekarang.
\end{abstract}

Kata Kunci: Komunikasi Pemasaran, Word of Mouth, Electronic Word of Mouth 


\section{Pendahuluan}

Perkembangan bisnis semakin diwarnai dengan varian usaha yang kreatif, menarik dan inovatif. Salah satunya adalah usaha kedai kopi yang menjadi persaingan bisnis saat ini, karena kebiasaan gaya hidup meminum kopi memang kian digemari oleh masyarakat Indonesia sampai saat ini. Kopi merupakan tanaman perkebunan yang sudah lama dibudayakan. Selain sumber pengahasilan rakyat, kopi menjadi komoditas andalan ekspor dan sumber devisa negara (Rahardjo: 2012:7). Kedai kopi menjadi tempat orang berkumpul dan beraktivitas sesuai dengan kegiatan mereka, menjadi tempat meeting dengan klien, tempat berkumpul dengan kerabat dan keluarga dan tempat untuk kegiatan keperluan konsumen masing-masing lainnya. Semakin banyaknya usaha kedai kopi, maka semakin ketat juga persaingannya.

Komunikasi sudah menjadi kebutuhan setiap hari untuk berinteraksi dengan sesamanya. Menurut Feriyanto dan Triana (2015:13), Komunikasi dapat dikatakan komunikatif apabila keduabelah pihak selain mengerti bahasa yang digunakan, juga mengerti makna dari apa yang disampaikan, bentuk komunikasi manusia termasuk bahasa, sinyal, bicara, tulisan, gerakan dan penyiaran.

Usaha kedai kopi yang memiliki pelanggan yang setia dan terus ramai berdatangkan pelanggan, memiliki rahasia tersendiri dalam menggait para pelanggannya. Hal tersebut diperkuat dengan pernyataan Peter dan Olson (2014:4) yang menyatakan bahwa, saat ini terdapat banyak perusahaan di dunia yang menjadi sukses karena mendesain organisasi secara keseluruhan untuk melayani mereka dan tetap dekat dengan mereka. Kedai kopi yang telah bertahan sampai berpuluh tahun seperti Kopi Es Tak Kie, tentu memiliki khas, prinsip dan komitmen yang dipegang kuat oleh pemilik kedai kopinya. Dalam ketahanan kedai Kopi Es Tak Kie yang sudah beroperasi selama 92 tahun sampai sekarang ini, di dalamnya didukung oleh kekuatan loyalitas pelanggan yang memiliki peran yang penting.

Pemasaran yang berdasarkan keintiman konsumen, sudah jauh bergeser dari konteks kepuasan konsumen. Konsumen saat ini, tak hanya lagi mencari sekadar kepuasan. Melainkan konsumen juga membutuhkan hubungan emosional terhadap suatu produk atau jasa yang dipilihnya. Hubungan emosional inilah yang nantinya bisa menjadi sel inti dari sebuah loyalitas karena tanpa loyalitas konsumen, posisi kita sebagai penyedia barang atau jasa jelas rawan (Kurnia, 2004:8). Berawal dari latar belakang diatas, peneliti memiliki fokus pertanyaan penelitian, "Bagaimana komunikasi pemasaran word of mouth dan electronic word of mouth dalam mempertahankan brand existence pada merek Kopi Es Tak Kie?" dengan tujuan penelitian untuk mengetahui dan menerapkan suatu komunikasi pemasaran yang digunakan Kopi Es Tak Kie dalam memelihara suatu usaha agar tetap bertahan lama.

\section{Metode Penelitian}

Untuk metode yang digunakan penulis dalam penelitian ini adalah penelitian kualitatif yang bersifat deskriptif. Penulis menggunakan penelitian kualitatif deskriptif karena penulis ingin memahami lebih dalam pada subjek dan objek penelitian secara sistematis, deskriptif dan akurat mengenai komunikasi pemasaran yang digunakan Kopi Es Tak Kie. Strategi penelitian yang digunakan peneliti adalah studi kasus, studi kasus adalah salah satu metode penelitian ilmu-ilmu sosial. Studi kasus merupakan strategi yang lebih cocok bila pokok pertanyaan suatu penelitian 
Nevelyn Anestya Herdian, Diah Ayu Candraningrum: Komunikasi Pemasaran Word of Mouth dan Electronic Word of Mouth dalam Mempertahankan Brand Existence (Studi Kasus pada Kopi Es Tak Kie)

berkenaan dengan " bagaimana" atau "kenapa" dan studi kasus yang menggunakan survei dan historis cocok untuk tahap deskriptif. Peneliti kualitatif perlu mendokumentasikan prosedur studi kasusnya dan untuk mendokumentasikan sebanyak mungkin langkah dalam prosedur tersebut (Yin, 2014:5). Lalu selain itu strategi peneltian yang penulis gunakan adalah bersifat deskriptif untuk menjelaskan fenomena sedalam-dalamnya, melalui pengumpulan data yang dapat beruapa hasil wawancara, catatan lapangan, foto, video, dan dokumentasi pribadi lainnya. (Moleong, 2012:11).

Subyek yang akan penulis jadikan narasumber penelitian adalah merek Kopi Es Tak Kie. Dan objek penelitian adalah Pemilik kedai Kopi Es Tak Kie. Penulis juga melibatkan pelanggan Kopi Es Tak Kie dari kedai yang berada di Glodok maupun yang di Lippo Mall Puri. Untuk menambah wawasan dan pengetahuan lebih lanjut mengenai budaya usaha pada orang Tionghoa, penulis juga melibatkan Eddy Prabowo Witanto sebagai informan budayawan Tionghoa.

Metode pengumpulan data yang penulis gunakan dalam penelitian ini adalah Observasi non-partisipan, wawancara, dokumen dan penelusuran data online. Untuk observasi non-partisipan, dimana penulis akan datang ke tempat penelitian tetapi tidak terlibat dalam kegiatannya. Lalu yang kedua, penulis menggunakan metode wawancara yang didasarkan pada interview baik secara standar maupun mendalam dan terstruktur. Untuk memperkuat penelitian, penulis juga menggunakan metode pengumpulan data berupa pengumpulan dokumen. Dapat berbentuk foto-foto, biografi, website dan karya-karya lainnya. Dan penelusuran data online, penulis akan melakukan penelusuran mengenai aktivitas merek Kopi Es Tak Kie pada media online.

Teknik pengolahan data yang penulis gunakan dalam penelitian ini adalah teknik data reduksi, yaitu merangkum, memilih hal-hal yang pokok, memfokuskan kepada hal yang penting. Selanjutnya menggunakan data display yaitu memahami apa yang terjadi, dan merencanakan kerja selanjutnya berdasarkan yang telah dipahami. Terakhir penarikan kesimpulan yaitu makna muncul dari data yang telah teruji kepercayaannya, kekuatannya, konfirmabilitasnya yaitu validitasnya (Emzir, 2012:129). Lalu, untuk teknik keabsahan data penelitian ini, menggunakan Triangulasi sumber, yaitu suatu informasi dapat diperoleh melalui waktu dan alat yang berbeda, seperti membandingkan data hasil pengamatan dengan data hasil wawancara, lalu membandingkan perkataan orang di depan umum dengan perkataan pribadi, dsb (Moleong, 2012:2:330).

\section{Hasil Temuan dan Diskusi}

Kopi Es Tak Kie adalah kedai kopi tua yang berada di ibu kota Jakarta. Kopi Es Tak Kie telah berdiri sejak 1927 dan masih beroperasi sampai sekarang. Nama Tak Kie sendiri berasal dari kata " Tak " yang berarti orang yang bijaksana, sederhana dan apa adanya. Sementara kata "Kie " yang artinya mudah diingat banyak orang. Nama ini tidak berubah sejak pertama kali didirikan. Maksud dari semua itu adalah bahwa pendiri kedai kopi ini ingin mengajarkan untuk selalu tampil sederhana dan kerja keras kepada penerusnya.

Tulisan hanzi “德記茶室” yang berada pada dibawah nama Kopi Es Tak Kie itu adalah Dé jì cháshì. " Dé jì " yang berarti nama Tak Kie itu sendiri, " chá " adalah teh dan " shì " adalah ruang. Jadi "Dé jì cháshì" adalah tempat minum teh Tak Kie. Kopi Es Tak Kie ini didirikan pertama kali oleh seorang perantau dari 
Tiongkok bernama Liong Kwie Tjong. Awalnya kedai ini hanyalah sebuah tempat warung kopi kaki lima yang berada di kawasan petak 9 (sembilan). Lalu, Putra Liong Kwie Tjong yaitu Liong Tjoen, generasi kedua, meneruskan usaha Kopi Es Tak Kie. Mulai dari generasi inilah, kedai Kopi Es Tak Kie mulai menetap di kedai kecil yang berada di gang Gloria.

Pada generasi ketiga, diturunkan kepada salah satu anak mereka dari 12 bersaudara, yaitu Latif Yulus alias Ayauw yang sekarang memegang kedai Kopi Es Tak Kie yang masih berada di Gang Gloria, Jl. Pintu Besar Selatan III No. 4 - 6 Glodok, Jakarta Barat. Seiring berjalannya waktu, pada tahun 2014. salah satu anak dari Ayauw yaitu Willy Yulus memilih untuk mencoba mengikuti jejak sang ayah. Willy mulai berfokus pada kedai Kopi Es Tak Kie dan menjadi generasi pendukung di dalamnya.

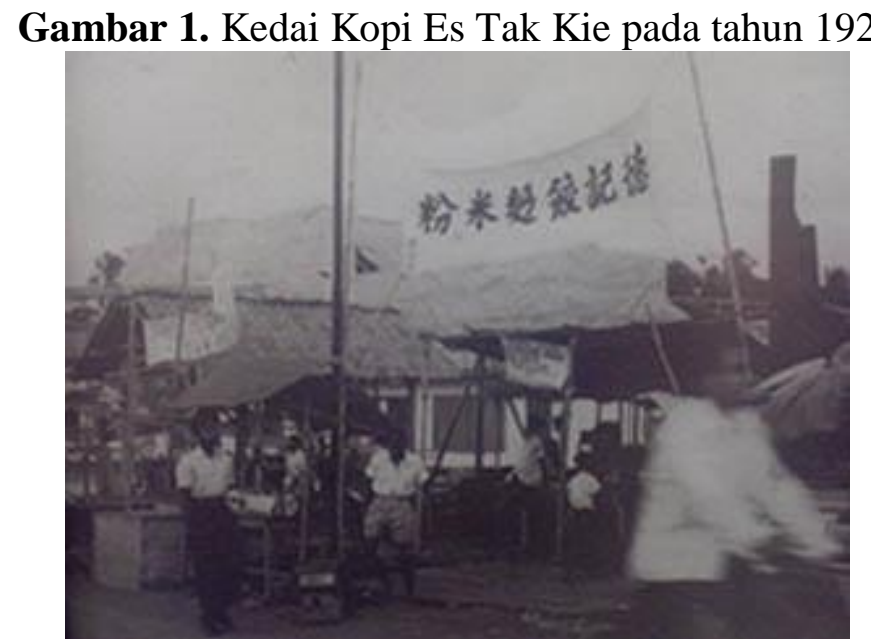

Sumber: www.kopiestakkie.com (2018)

Willy mulai menyadari bahwa banyak orang mengenal Kopi Es Tak Kie ini, namun mayoritas yang mengetahuinya adalah orang tua yang berusia sekitar 50-70 tahun. Banyak pula generasi muda yang belum tahu dan mengenal Kopi Es Tak Kie. Hal inilah yang mengilhami Willy hingga akhirnya berinisiatif untuk menggelar bazaar di pusat pertokoan supaya lebih bisa mendekatkan diri dengan kaum milenial. Hal ini juga termasuk dalam upaya mempertahankan eksistensi merek kedai Kopi Es Tak Kie (brand existence). Willy mencoba menyesuaikan dengan era yang sekarang dimulai dari melakukan event bazaar di mall, membuka outlet di mall dan berpromosi di media sosial.

Dalam mempertahankan brand eksistensi Kopi Es Tak Kie sampai hari ini, Latif Yulus sebagai generasi ketiga telah bekerja dengan orang tuanya sedari kecil saat semasa sekolah. Secara tidak langsung, Latif Yulus melihat dan belajar bagaimana cara orangtuanya bekerja dan cara melayani pelanggan dengan baik. Latif juga belajar memegang prinsip dan komitmen yang telah diajarkan oleh orangtuanya untuk mengelola kedai Kopi Es Tak Kie dengan sebaik-baiknya. Walaupun Kopi Es Tak Kie ini sudah berumur 92 tahun, tetapi setiap hari Kopi Es Tak Kie selalu tetap diminati oleh para pelanggan dari dalam negri sampai luar negri.

Kopi Es Tak Kie memiliki keunikan mereka sendiri yaitu masih mempertahankan suasana kedai kopi zaman dahulu yang tidak pernah dirubahnya. Mulai dari bangunannya, interior di dalam kedai, meja dan bangku yang masih dipakai dari zaman dahulu hingga sekarang yang masih kokoh. Untuk memasuki 

$\mathrm{Kie})$

kedai Kopi Es Tak Kie yang berada di Glodok juga tidak mudah menemukannya, karena mereka tidak memiliki palang nama yang mudah dilihat. Selain itu, Kopi Es Tak Kie berada di gang kecil yang sederetan hampir berisikan oleh penjual makanan. Bahkan di depan kedai mereka, terdapat banyak sekali penjual makanan sekba, nasi campur, bakmi dan lainnya. Berdasarkan hasil wawancara penulis terhadap pemilik dan pelanggan dari Kopi Es Tak Kie, dapat disimpulkan bahwa Kopi Es Tak Kie dapat bertahan karena salah satu alasannya mereka memiliki kekuatan word of mouth yang disalurkan oleh kepuasaan pelanggan yang pernah berdatangan di sana. Pelanggan yang merasa puas akan pelayanan dan makanan serta meninuman yang disediakan, secara tidak keberatan dan memiliki inisiatif sendiri untuk mengajak para kerabat, saudara dan keluarga untuk ikut mencoba Kopi Es Tak Kie.

Pelanggan Kopi Es Tak Kie juga banyak berdatangan karena hasil rekomendasi dari keluarga seperti orangtua mereka dan juga dari teman-teman yang mem-posting foto atau video di media sosial saat berada di Kopi Es Tak Kie. Banyak pelanggan Kopi Es Tak Kie berasal dari pelanggan turun-temurun, dimana kakeknenek atau bapak-ibunya dulu atau sekarang sering pergi ke Kopi Es Tak Kie.

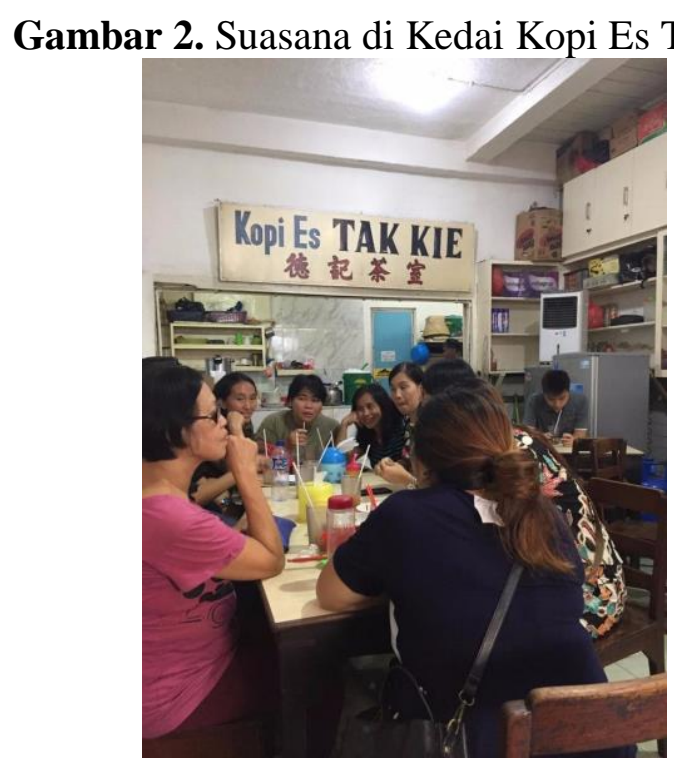

Sumber: Dokumentasi Pribadi (2018)

Informasi dari mulut ke mulut merupakan komunikasi yang sederhana, tidak memakan banyak biaya, terpercaya dan memberikan bukti kuat. Karena pengirim informasi tersebut memberitakan baik atau buruk pengalamannya secara objektif dengan tanpa paksaan dan tanpa dibayar. Sehingga informasi bersifat jujur, hal ini sesuai dikatakan oleh Nielsen yang dikutip oleh Whitler (2014) di www.forbes.com, mengatakan bahwa 92\% konsumen lebih percaya pada rekomendasi dari teman dan keluarga dari pada iklan. Hal ini menjadi bukti bahwa kekuatan Kopi Es Tak Kie dapat bertahan lama karena sering berlangsungnya komunikasi pemasaran secara Word of Mouth oleh para pelanggan. Latif Yulus selaku pemegang Kopi Es Tak Kie di generasi ketiga menyatakan bahwa mereka sedari dulu tidak memiliki komunikasi pemasaran secara khusus hanya mengandalkan dari kepuasaan pelanggan yang nantinya kepuasaan itu akan disebar oleh para pelanggannya yang akan mendatangkan pelanggan baru lagi.

Disisi lain, Kekuatan terbesar Kopi Es Tak Kie dalam bersaing dan mampu bertahan hingga sekarang ini dikarenakan besarnya peran Centre of Community yang 
dimiliki Kopi Es Tak Kie. Gagasan ini disampaikan dari hasil wawancara oleh budayawan Tionghoa, Eddy Prabowo Witanto. Kopi Es Tak Kie mampu bersaing dengan kedai kopi lainnya dan menjadi Centre of Community bagi para orang-orang Tionghoa zaman dulu yang berpindah ke Asia Tenggara, khususnya di Indonesia daerah Jakarta. Menjadi centre of community yang berarti Kopi Es Tak Kie adalah basecamp yang dapat dikatakan nyaman dan tepat, karena setiap anggota atau kelompok merasa puas akan pelayanan dan kualitas yang diberikan. Dan Kopi Es Tak Kie mampu mempertahankan hubungan pertemanan pada setiap kelompok yang menjadi pelanggan setia mereka. Hal ini sesuai dengan Herdana (2015:3) yang mengatakan bahwa suatu produk dapat dikenal luas oleh masyarakat bergantung dari eksistensi merek tersebut di pasaran. Merek suatu produk haruslah dikomunikasikan dengan tepat agar bisa masuk ke dalam benak konsumen sehingga eksistensi merek dapat terbentuk.

Kasus kebangkrutan terjadi pada perusahaan Kodak. Kodak terlambat untuk berinovasi dan tidak mengikuti perkembangan era. Perusahaan Kodak yang didirikan tahun 1888 oleh George Eastman. Perusahaan bernama Eastman Kodak ini masih sangat terkenal di tahun 1980an, sampai mulai terkena kesulitan keuangan yang mengumumkan bahwa perusahaan Kodak mengalami laba anjlok sampai $73 \%$. Sebenarnya Kodak sudah mempunyai teknologi untuk membuat kamera digital pada 1975, tapi sengaja tidak diluncukan dulu karena takut membunuh bisnis rol film fotonya. Sayangnya, konsumen berkata lain dan ingin kamernya serba digital sehingga akhirnya Kodak telat meluncurkan produk kamera digital. Pada tahun 2009, Kodak menghentikan produksi film fotonya setelah dipasarkan selama 74 tahun. Tiga tahun kemudian, Kodak melayangkan permohonan pailit (dikutip : https://finance.detik.com/berita-ekonomi-bisnis/d-2188089/4-perusahaan-yang-duluterkenal-kini-sudah-menghilang/5).

Tidak ingin hal yang terjadi pada Kodak akan terjadi pada merek Kopi Es Tak Kie. Maka pada saat ini, Willy berusaha untuk membangun suatu mindset menghidupkan nostalgia masyarakat dan rebranding dengan menambahkan nama Kopi Es Tak Kie dengan Heritage Coffee yang mengubah pandangan orang, bahwa Kopi Es Tak Kie adalah sebuah merek yang tua dan masih ada sampai sekarang, dan tidak salah untuk dicoba.

Pelanggan setia Kopi Es Tak Kie sedari dulu yang sudah berumur di antara 5070 tahun, sudah mulai termakan oleh usia. Dengan seiring perkembangan zaman di era digital dan teknologi, maka di bawah generasi 3 yaitu generasi pendukung mulai aware dengan era digitalisasi. Willy berharap Kopi Es Tak Kie semakin dikenal banyak orang mengenai cita rasa kopi dan sejarahnya sehingga akan terus tetap hidup kedepannya.

Hal ini sesuai dengan pernyataan dari Candraningrum (2017), yang mengatakan bahwa sebuah perusahaan besar yang menjadi raja di pasar selama kurun waktu tertentu, ternyata dapat jatuh dan kalah oleh teknologi, oleh karena itu butuh membangun branding perusahaan dengan media sosial dan cyber lainnya seperti email, blog, website perusahaan dan lainnya dapat membantu membangun hubungan perusahaan dengan konsumennya. Dalam kehidupan saat ini yang sudah beralih pada era digitalisasi, Willy mulai mencoba meluaskan dan semakin mengangkat nama Kopi Es Tak Kie dengan mengadakan event bazaar di beberapa mall kota besar, membuka sosial media untuk tetap engaged dengan pelanggan seperti memberikan informasi dan mendengar masukan dari pelanggan serta membuka outlet maupun di mall untuk menjangkau pelanggan agar lebih mudah 

Kie)

untuk menikmati Kopi Es Tak Kie. Willy berusaha untuk membangun suatu mindset menghidupkan nostalgia masyarakat dan rebranding dengan menambahkan nama Kopi Es Tak Kie dengan heritage coffee yang mengubah pandangan orang bahwa Kopi Es Tak Kie adalah sebuah merek yang tua dan masih ada sampai sekarang, dan tidak salah untuk dicoba.

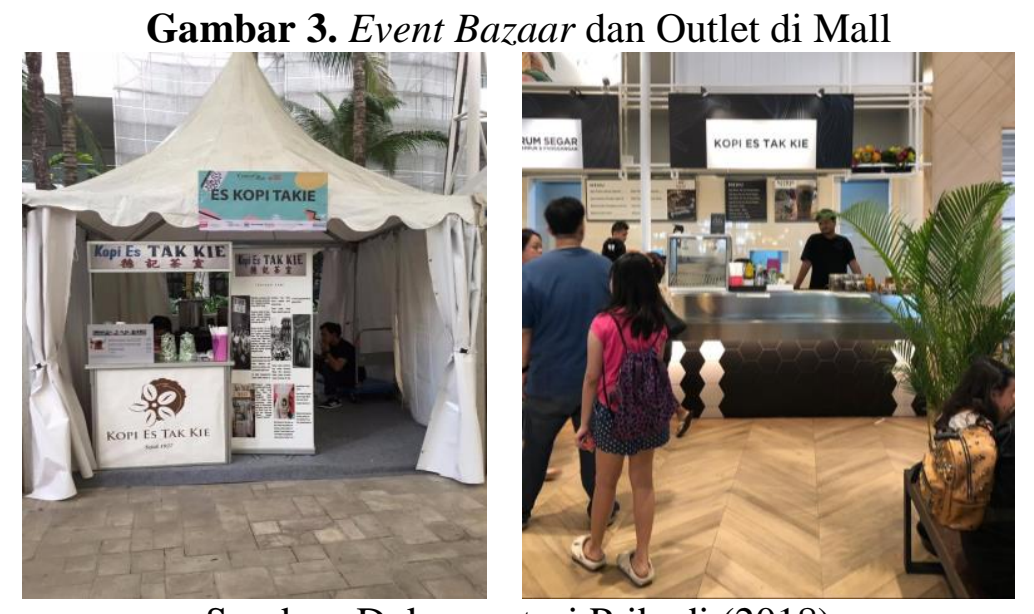

Sumber: Dokumentasi Pribadi (2018)

\section{Simpulan}

Berdasarkan hasil penelitian yang dilakukan oleh peneliti mengenai komunikasi pemasaran word of mouth dan electronic word of mouth yang digunakan Kopi Es Tak Kie untuk mempertahankan Brand Existence, peneliti menemukan bahwa Kopi Es Tak Kie hanya menggunakan bentuk komunikasi pemasaran word of mouth yang dipakai oleh generasi 1 sampai generasi ke-3. Berbeda dengan generasi yang sebelumnya, generasi pendukung Kopi Es Tak Kie memakai komunikasi pemasaran melalui electronic word of mouth dalam memberikan informasi dan melakukan engaged lebih terhadap konsumennya.Pada generasi pendukung ini memilih untuk berpromosi sesuai dengan era jaman sekarang yang menjurus kepada teknologi digital. Selain itu, untuk liputan dari media televisi, koran dan majalah, mereka tidak pernah membayar untuk beriklan. Tetapi karena memang keunikan Kopi Es Tak Kie itulah yang menjadikan kedai kopi ini menjadi objek liputan yang menarik bagi media.

Berdasarkan hasil wawancara peneliti dengan pemilik Kopi Es Tak Kie yang ada pada 2 generasi, serta narasumber lainnya seperti pengunjung dan budayawan Tionghoa, dapat disimpulkan bahwa komunikasi pemasaran yang word of mouth pada merek Kopi Es Tak Kie berperan penting bagi kelangsung usahanya. Karena sebelum generasi pendukung membuka komunikasi pemasaran Electronic Word of Mouth, Kopi Es Tak Kie dikenal melalui dari mulut ke mulut saja dari jaman ke jaman. Loyalitas pelanggan mereka pun terjadi karena faktor turun temurun, dimana salah satu kakek atau bapak mereka yang sering ke Kopi Es Tak Kie memberitahukan bahwa kakek atau bapak mereka dulu sering pergi kesana. Pada akhirnya mereka akan mengajak anak serta cucu mereka untuk ikut datang dan menjelaskan bagaimana Kopi Es Tak Kie itu menjadi salah satu kedai favorit mereka.

Pemegang generasi ke-3 Kopi Es Tak Kie saat ini jika sudah tidak memegang lagi kedai kopi tersebut, tidak akan langsung turun kepada generasi pendukung 
melainkan generasi ke-3 akan terus ada dan diteruskan kepada saudara adik-adik dari Bapak Ayauw yang masih tergolong generasi ke-3 tersebut. Dan komunikasi pemasaran melalui Electronic Word of Mouth masih dalam tahap perkembangan tetapi sangat membantu konsumen untuk mengakses informasi lebih banyak lagi tentang Kopi Es Tak Kie secara mudah. Tetapi tidak dipungkiri bahwa Kopi Es Tak Kie memang harus sudah mengikuti zaman dengan era digital. Karena ke depannya generasi milenial yang akan lebih dominan dan mereka sangat akrab dan bergantung sekali akan informasi yang berada di internet. Untuk melewati tahap-tahap loyalitas pelanggan dan membangun kepercayaan membutuhkan waktu, konsisten dan engagement yang kuat terhadap konsumen.

\section{Ucapan Terima Kasih}

Penelitian ini dapat terlaksana dan terwujud dengan baik atas bantuan kebaikan dari Tuhan Yang Maha Esa. Dan atas bantuan dari Latif Yulus dan Willy Yulus selaku pemegang Kopi Es Tak Kie, yang telah memberikan kesempatan kepada peneliti untuk melakukan penelitian. Selain itu terimakasih ditujukan kepada para narasumber peneliti, yaitu Bpk. Eddy Prabowo selaku budayawan Tionghoa, Bpk. Alex, Ibu. Mimi, Bpk. Lili Sumantri, Kak Derwin Japara dan Kak Vinny Stefany selaku informan pelanggan Kopi Es Tak Kie yang sudah bersedia membantu secara sukarela untuk peneliti melakukan penelitian ini.

Rasa terimakasih yang sebesar-besarnya yang ditujukan kepada Ibu Diah Ayu Candraningrum, S.T., M.B.A., M.Si selaku dosen pembimbing yang telah senantiasa bersedia membimbing peneliti dengan semaksimal dan sebaik-baiknya, dari awal peneliti melakukan penelitian hingga pada akhir penelitian. Serta tidak lupa juga peneliti mengucapkan terima kasih kepada keluarga dan teman-teman yang selalu memberikan dukungan doa, semangat dan bantuan melalui pengetahuan serta waktu yang diluangkan untuk membantu peneliti dalam menyelesaikan penelitian ini.

\section{Daftar Pustaka}

Feriyanto, Andri dan Triana, Endang Shyta. 2015. Komunikasi Bisnis " Strategi Komunikasi dalam Mengelola Bisnis “. Yogyakarta: MEDIATERA.

Emzir. 2012. Metodologi Penelitian Kualitatif Analisis Data. Jakarta: Rajawali Pers. Kurnia, Kafi. 2004. Anti Marketing. Penerbit : PT. Andal Krida Nusantara.

Moleong, Lexy J. 2012. Metodologi Penelitian Kualitatif. Bandung : PT Remaja Rosdakarya.

Peter, J.Paul \& Olson, Jerry C. 2014. Perilaku Konsumen dan Strategi Pemasaran. Jakarta: Salemba Empat.

Rahardjo, Pudji. 2012. Kopi (Panduan Budi Daya dan Pengolahan Kopi Arabika dan Robusta). Jakarta: Penebar Swadaya.

Sugiyono. 2016. Metode Penelitian Kuantitatif, Kualitatif, dan R\&D. Bandung: Alfabeta.

Candraningrum. D.A. (2017). Jurnal Gangguan Komunikasi Publik dan Penurunan Brand Engagement di Perusahaan Toys"R"Us. (Diakses pada 17 Oktober 2018).

http://www.jurnal.unsyiah.ac.id/JKG/article/view/9322

Detik Finance. (2013). 4 Perusahaan Dulu yang Terkenal Kini Sudah Menghilang (Diakses pada 19 Januari 2019) 
Nevelyn Anestya Herdian, Diah Ayu Candraningrum: Komunikasi Pemasaran Word of Mouth dan Electronic Word of Mouth dalam Mempertahankan Brand Existence (Studi Kasus pada Kopi Es Tak Kie)

https://finance.detik.com/berita-ekonomi-bisnis/d-2188089/4-perusahaan-yang duluterkenal-kini-sudah-menghilang/5

Herdana, Auditya. (2015). Analisis Pengaruh Kesadaran Merek (Brand Awareness) Pada Produk Asuransi Jiwa Prudential Life Assurance (Studi Pada Pru Passion Agency Jakarta). (Diakses pada 1 November 2018).

https://ejournal.unsrat.ac.id/index.php/jrbm/article/view/7524

Whitler, K. A. (2014). Why Word of Mouth Marketing Is The Most Important Social Media. (Diakses pada 5 Desember 2018). http://www.forbes.com/sites/kimberlywhitler/2014/07/17/whyword-ofmouth-marketing-is-the-most-important-social-media/ 